\title{
General Purpose Technology: The Blockchain Domain
}

\author{
Elona Marku ${ }^{1}$, Manuel Castriotta ${ }^{1}$, Michela Loi $^{1} \&$ Maria Chiara Di Guardo ${ }^{1}$ \\ ${ }^{1}$ Department of Economics and Business, University of Cagliari, Cagliari, Italy \\ Correspondence: Elona Marku, Department of Economics and Business, University of Cagliari, Via Sant'Ignazio \\ 74, 09123 - Cagliari, Italy. E-mail: elona.marku@unica.it
}

Received: September 8, 2020

Accepted: October 20, 2020

Online Published: October 30, 2020

doi:10.5539/ijbm.v15n11p192

URL: https://doi.org/10.5539/ijbm.v15n11p192

\begin{abstract}
Blockchain is an emerging evolutionary paradigm expected to revolutionize existing business models and impact the world economy and society. Its potential pervasiveness is increasingly drawing the interest of academics, practitioners, firms, financial institutions, and national governments, who define it as a general purpose technology (GPT). Although it may take considerable time to affirm a technology as general, in this phase of the blockchain domain's evolution, to what extent can it be considered a GPT? By adopting a patent co-classifications analysis, this paper aims at disentangling the blockchain technology structure, development, and potential future trends. We analyzed blockchain international patents issued from 2008 to 2018 . Results showed a proliferation of the inventive activity and a significant increase in the diversity of technology fields, capturing the blockchain's GPT traits. Moreover, our patent measures detected technology dynamics related to 'space for improvement' and 'pervasiveness' that commonly characterize GPTs. Our study contributes to the technology innovation literature by uncovering the emergence and evolutionary path of a GPT, and our results provide an empirical basis on which managers could build technology-related decisions to enable appropriate firms' innovation strategies.
\end{abstract}

Keywords: blockchain, general purpose technologies, patents, technology emergence

\section{Introduction}

Blockchain is a decentralized transaction and data management technology developed first for the Bitcoin cryptocurrency. It was ideated in 2008 as a secure means for the automated execution of smart contracts in peerto-peer networks (Andoni et al., 2019; Miau \& Yang, 2018). With blockchain, we can imagine a world in which contracts are embedded in digital code and stored in a transparent, shared database, where they are protected from deletion, tampering, and revision (Iansiti \& Lakhani, 2017; Holotiuk, Pisani, \& Moormann, 2019). It may seem this technology to be primarily related to the financial sector, but the concept behind it is disrupting many productive sectors affecting the whole society (Chuen \& Deng, 2017; Iansiti \& Lakhani, 2017; Tapscott \& Tapscott, 2017; Felin \& Lakhani 2018; Andoni et al., 2019).

Recent studies pointed out how blockchain networks will disrupt different contexts and application fields (MarsalLacuna, 2018). However, although the sudden rise in blockchain technology has caught the media's attention in recent years, there is still a scarcity of academic literature on the subject, especially regarding a better understanding of the innovation scenario and the evolutionary dynamics of this specific technology domain. For this reason, the present study aims at providing a comprehensive overview by disentangling the blockchain technology structure, depicting the technology landscape, identifying the most active areas and innovation trends, and highlighting the major players.

Moreover, technology innovation literature has widely shown patents' crucial role as a meaningful instrument to measure innovation performance (Trajtenberg, 1990; Makri, Hitt, \& Lane, 2010), to capture the multifaceted dimensions of technology (Hall, Jaffe, \& Trajtenberg, 2001; Harrigan, Di Guardo, Marku, \& Velez, 2017), to track the knowledge flows and spillovers (Jaffe, 1986), and to monitor convergence and emerging technologies (Ardito, Petruzzelli, \& Albino, 2016; Curran \& Leker, 2011).

We analyze 964 international patents globally protected through the World Intellectual Property Organization (WIPO) issued from 2008 to 2018 ( $1^{\text {st }}$ semester). By adopting a patent co-classification analysis, we map and visualize the structure of the blockchain technology and the links between the different technology elements, highlighting boundary and core technologies. Besides, we use a new approach for mapping and visualizing a sector's profile and evolution by focusing on fine-grained patent data such as the Derwent classification codes 
(Calcagno, 2008; Luan, Liu, \& Wang, 2013).

The remainder of the paper is structured as follows. In Section 2, we examine the literature background, describing the blockchain technology and the traits of GPT; particular attention is paid to studies on patent analysis. Section 3 includes the methodology applied, while Section 4 describes the results observed. Finally, Section 5 discusses the implication of results and concludes.

\section{Literature Review}

\subsection{The Blockchain Technology}

"Blockchain is the first digital medium for value and will fundamentally transform how we move, store, and manage assets and information. Every industry is affected. Understanding this technology will be critical to surviving in the next era of the digital economy."

Alex Tapscott (Co-founder, Blockchain Research Institute)

Blockchain is an emerging revolutionary technology expected to redefine the digital economy by disrupting existing business models with a broad impact on diverse industries (Swan, 2015; Tapscott \& Tapscott, 2017). It is often called the 'Internet of value' and is intended to replace the current 'Internet of information' (Tapscott \& Tapscott, 2017). With blockchain, we can imagine a world in which contracts are embedded in digital code and stored in a transparent, shared database, where they are protected from deletion, tampering, and revision (Iansiti \& Lakhani, 2017; Holotiuk et al., 2019). Indeed, transactions in business, finance, international collaboration, and government's tool chests are intended for radical transformation; a change will be crucial on business, technology, processes, structures, and people. Blockchain further challenges the current competitive dynamics as it sharply reduces entry barriers for new players fostering a more competitive ecosystem (Zalan, 2018).

Blockchain, ideated in 2008 by Satoshi Nakamoto, was developed first for the Bitcoin cryptocurrency. This technology is conceived as a decentralized transaction and data management technology representing a secure means that allows for the automated execution of smart contracts in peer-to-peer mass collaboration networks (Andoni et al., 2019). Without the need for a powerful central authority (bank or government), the blockchain as a distributed ledger can host a rising number of records 'chained' linearly in blocks that can be spread across multiple institutions or countries. These records are encrypted following chronological order in such a way that makes them not revisable; however, all changes are visible to all chain's participants. The database can be shared and validated by anyone having the appropriate permissions, and it can be either public or private.

Blockchain is the result of innovations at the intersection of computer science, cryptography, and economics (Zalan, 2018). Since its conceptualization, blockchain has experienced a rapid evolution (Efanov \& Roschin, 2018), shifting from Blockchain 1.0 that primarily focused on cryptocurrency to Blockchain 2.0 connected to the digital economy, and more recently, it has spawned in Blockchain 3.0 conceived as an essential technology for the digital society (Efanov \& Roschin, 2018; Swan, 2015). Blockchain 1.0 can be translated as cash for the Internet connecting finances in the same way the Internet of Things (IoT) connects machines. Blockchain 2.0 refers to contracts exceeding simple cash transactions and involving financial applications such as stocks, bonds, loans, mortgages, futures, smart property, and smart contracts. Last, Blockchain 3.0 is blockchain applications beyond currency, finance, and markets encompassing government, health, science, culture, and art (Swan, 2015).

Research on the blockchain is in its initial stage. Management studies have investigated the new dynamics related to trust (Hawlitschek et al., 2018; Seidel, 2018; Veuger, 2018), value creation (Pazaitis, De Filippi, \& Kostakis, 2017), and supply chain (Önder \& Treiblmaier, 2018). Other studies have examined the impact of blockchain technology on the nature of financial transactions related to business ethics (Dierksmeier \& Seel, 2018), global inequality and unnecessary poverty (de Soto, 2017), as well as the rise of new entrepreneurship opportunities, including venture financing (Fisch, 2019; Larios-Hernández, 2017).

Practitioner-oriented research has primarily focused on how to make blockchain applications a reality (Lacity, 2018). In particular, studies have investigated how blockchain will change organizations and competition (Tapscott \& Tapscott, 2017), what problems it will solve (Felin \& Lakhani, 2018), and how much longer will take the process (Iansiti \& Lakhani, 2017). Several sectors have been analyzed, the financial and healthcare industries (Engelhardt, 2017; Yoo, 2017), and different contexts have been considered, both urban and rural (Marsal-Llakuna, 2018).

From a technical perspective, most studies on blockchain have investigated the aspects of the potential applications of the technology such as identity management, intelligent transportation, supply-chain management, mobilecrowd sensing, agriculture, Industry 4.0, Internet of energy, and security in mission-critical systems (Ferrag et al., 2018). Special attention is devoted to Bitcoin (Khalilov \& Levi, 2018), the Internet of vehicles (Dorri, Steger, Kanhere, \& Jurdak, 2017; Huang, Xu, Wang, \& Liu, 2018), the Internet of energy and cloud (Xu, Wang, \& Guo, 
2018), Fog computing (Huang et al., 2018), the Internet of healthcare things (Esposito, De Santis, Tortora, Chang, \& Choo 2018), IoT devices (Gu et al., 2018), among others.

Last, the different research streams highlight the vast complexity of the phenomenon and point out the concern about its evolution and impact on firms, economies, and society. Thus, the lack of studies on unveiling the existing technology structure increases the difficulties of sensing and seizing opportunities and reacting to new competitive innovation dynamics. This context makes salient a more complete overview of the technology's emergence, evolution, and potential future blockchain technology trends.

\subsection{General Purpose Technologies}

GPTs are revolutionary changes from current technological trajectories that enable increasing returns to scale and long-run economic growth (Bresnahan \& Trajtenberg, 1995; Korzinov \& Savin, 2018; Syverson, 2013). Since the seminal article of Bresnahan and Trajtenberg (1995), there is great interest around the dynamics related to GPTs (Ardito et al., 2016; Bresnahan, 2010; Conti, Gambardella, \& Novelli 2019; Gambardella \& McGahan, 2010; Gambardella \& Giarratana, 2013; Conti, Gambardella, \& Novelli, 2019; Shea, Grinde, \& Elmslie, 2011).

Following prior research, we conceive GPTs as technological solutions able to subsequently connect to a broad range of different applications or development technologies that improve and spread rapidly in many industries (Bresnahan \& Trajtenberg, 1995; Gambardella \& Giarratana, 2015). GPTs are characterized by high technological dynamism, pervasiveness, and innovation complementarities. The latter is comprehended as a combination of both space for technological improvement and capability to be applied to a wide range of different sectors (Bresnahan, 2010; Helpman \& Trajtenberg, 1994; Lipsey, Carlaw, \& Bekar, 2005; Youtie, Iacopetta, \& Graham, 2008).

Although there is no unifying view about the emergence of a GPT (Korzinov \& Savin, 2018), existing studies point out that in the first stage of emergence, GPT is in a primitive state. However, the feedback from the application sector makes it progress over time, and it "eventually comes to be widely used, to have many uses, and to have many spillover effects." (Lipsey et al., 2005, p. 98). Hence, a GPT requires, on the one hand, scientific advances in the basic technology — regarding functionality, quality, or production efficiency - while on the other hand, it involves technological spawning and progress in its various applications (Shea et al., 2011).

The emergence of a new technology is followed by uncertainty and concerns regarding changes in firms' productivity, consumption patterns, and socioeconomic relationships (Youtie et al., 2008). Thus, most of the GPTs involve structural changes (organization of work, firm management, industry concentration, and supporting infrastructure) to become effective. Lipsey and colleagues (2005) called them 'Transforming GPT' when they generate a massive impact on the economy, society, and political structures. Nevertheless, there are cases of GPTs for which we do not observe these radical changes, for instance, the laser technology.

Additionally, GPTs require a long-run time from their emergence to a socioeconomic impact (Lipsey et al., 2005). This aspect highlights that the generality of specific technology can be observable only ex-post. Recently, Korzinov and Savin (2018) used network analysis to investigate the emergence and diffusion of GPTs. They observed that knowledge is an essential condition for technological convergence and especially for the GPT adoption. The links between the different technological elements can be an indicator of their capability to be combined in an invention that has economic value. Also, a specific technology's network centrality denotes its potential to become a GPT (Korzinov \& Savin, 2018). Higher will be the links between the technological elements, and higher will be the speed of diffusion of the GPT.

\subsection{Patent Analysis}

Patent analysis is one of the most suitable means to examine technology's main features and potential GPT traits (Ardito et al., 2016; Moser \& Nicholas, 2004). Patent documents are a valuable and effective source for unveiling the inventions' technological landscape (Kim \& Bae, 2017; Trappey, Wu, Taghaboni-Dutta, \& Trappey, 2011). Expressly, patents grant limited-life exclusive rights in exchange for disclosing the technology (Trappey et al., 2011). As such, they play a crucial role in capturing the value produced by the R\&D efforts and disclosing it in exchange for protection (Oh, Cho, \& Kim, 2014).

Patent documents are widely used in technology innovation literature to assess innovation performance (Di Guardo, Harrigan, \& Marku, 2019; Hall et al., 2001; Harrigan, Di Guardo, \& Marku, 2018) and investigate technology structure, evolution, and trends (Ardito et al., 2016; Curran \& Leker, 2011; Karvonen \& Kässi, 2013; Lee, Park, \& Kang, 2018; Marku et al., 2019). Also, patents provide an essential representation of imminent technological breakthroughs by reflecting the platforms upon which future innovations will be based (Ahuja \& Lampert, 2001).

Accordingly, most of the existing research on GPT's field has used a patent citation-based technique to capture the phenomenon's high complexity (Moser \& Nicholas, 2004). Specifically, the generality measure often exploits the 
information included in forward citations. The higher the technological breadth of the inventions built upon a focal technology, the higher its generality of applicability (Hall et al., 2001; Hall \& Trajtenberg, 2006). The drawback consists of a specific technology's time required to be cited, impeding to observe the diffusion across the different technological domains. Hall and Trajtenberg (2006) observed that patent citation analysis could capture a broad perception of general technologies. Still, there is a fundamental difficulty in constructing measures of how generalpurpose a technology is.

This paper adopts a patent co-classification analysis from a network-based perspective to overcome the drawbacks of forward citations. Technology innovation literature provides two widely used techniques to map and unveil the structure of science and technology, patent co-citation analysis and patent co-classification analysis (Curran \& Leker, 2011; Karvonen \& Kässi, 2013; Zupic \& Čater, 2015). The main difference between these techniques regards the greater suitability of patent co-citation analysis for in-depth investigation of the technology flows between different elements (i.e., at inventor level). Instead, patent co-classification is more appropriate to map and visualize the technology structure and the connections between two or more technologies within a broad technological space (Leydesdorff, 2008; Luan et al., 2013).

Patent co-classification uses fine-grained information regarding the technological classification/s of an invention through multiple classification codes assignments (Luan et al., 2013). When two or more technological elements combined have generated an invention, the relatedness between these components is strong. Looking at the technological space and examining a broad set of patented inventions, the links between the different technologies and their degree of centrality allow the emergence of specific structures of a sector (Lee, Kang, \& Shin, 2015; Park \& Yoon, 2014). Because of its nature, the patent co-classification analysis can bring out the technology structure, considering the most recent patent production of an industry or a technological landscape.

\section{Methodology}

To investigate the blockchain domain features, we collected all patent applications from 2008 to the first semester of 2018. We retrieved patent data from the Derwent Innovation Index (DII) as it is one of the more comprehensive worldwide patent databases. We focused on blockchain international patents globally protected through WIPO. In this way, we could consider the most relevant patents in a global scenario and reduce bias in national/regional patent activity (Criscuolo \& Verspagen, 2008). To identify blockchain patents, we searched for all WIPO patents that contained in their title, claims, or abstract the word 'blockchain' or 'block chain'. This search led to 964 patent applications that composed the sample under scrutiny. We collected information on technology classification, application year, publication year, country of first protection, assignee name. Besides, we gathered the backward patent citations, including their technology classification, application year, and publication year.

Furthermore, differing from prior research that primarily uses IPC classification codes, we adopted the Derwent classification system's manual codes. When applying the patent co-classification approach, the IPC classification system presents several issues related to the high number of IPC codes available and the hierarchical patent classification system used (Luan et al., 2013). Instead, the Derwent classification system characterized by higher parsimony is more accurate for the patent co-classification analysis (Calcagno, 2008; Harrigan et al., 2017).

Following prior studies on patent and bibliometric fields and consistently with the aim of the paper, we adopted cluster analysis and multidimensional scaling to perform the patent co-classification analysis (Castriotta \& Di Guardo, 2016; Castriotta et al., 2019; Di Guardo \& Harrigan, 2012; Loi, Castriotta, \& Di Guardo, 2016; Marku et al., 2019). From an operational point of view, co-classifications can be represented by a frequency matrix of cooccurrences of paired classification codes included in patents (Curran \& Leker, 2011; Karvonen \& Kässi, 2013). We retrieved the co-classification codes frequencies for each patent and compiled them into a raw matrix. From a network analysis perspective, the multivariate analysis of the aggregate similarity relationships between the patent classification codes reveals the patents' technological structure referring to the blockchain landscape.

In this paper, for the mapping, clustering, and visualization of the blockchain domain's technology structure, we used the Gephi Graph Visualization and Manipulation software (version 0.9.2; NetBeans 8.2). We performed a coclassification analysis and basic descriptive analysis to produce an indication of the nodes. Furthermore, we performed additional analysis regarding the network diameter, average path length, density (proportion of the potential network connections that are actual connections), average degree (an average calculation of the number of edges connected to each node), among other calculations (Janse van Rensburg et al., 2018). Finally, we adopted a cluster analysis as a common technique well suited to find subgroups in a field and gather the innovation similarity among technologies (McCain, 1990). 


\section{Results}

\subsection{Descriptive Results}

Figure 1 summarizes the number of patent applications compared to the number of patent publications from 2008 to the first semester of 2018. Changes in the number of patent applications indicate the speed of new technical knowledge generation, while patent publications' changes capture the amount of new knowledge that is disclosed. Results show the exponential growth of the technological outputs that increase from 3 patent applications in 2008 to 304 ones in the first six months of 2018 . When we consider the publication year, in 2018 ( $1^{\text {st }}$ semester), the number reaches 660 patents.

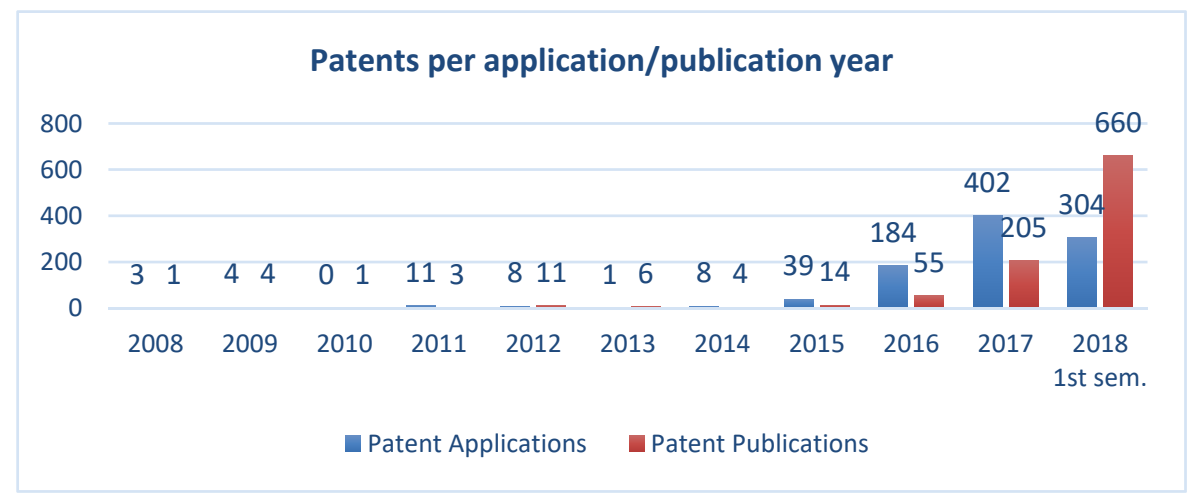

Figure 1. Number of patent applications vs. patent publications for each application year

Figure 2 shows the countries/regions where firms filed for initial protection, uncovering where the blockchain technology was developed. Firms located in the United States seem to be predominant in the international scenario. They are followed by China, the United Kingdom, Korea, the European region, Japan, Germany, Australia, and India.

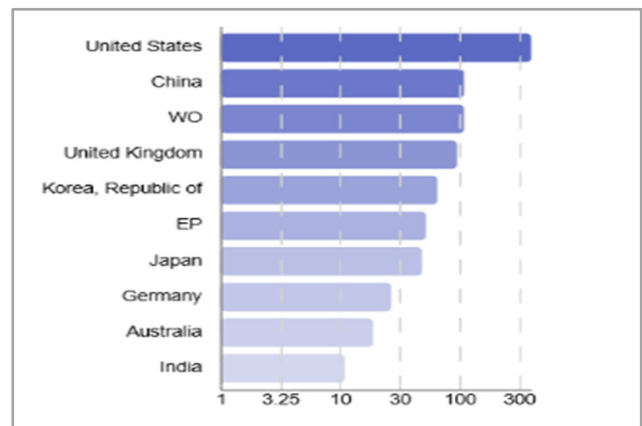

Figure 2. Countries/Regions where blockchain technology was developed (2008-2018 $1^{\text {st }}$ semester)

Moreover, to offer more insights about the major players and their technology competition, we investigated the most influential actors within the blockchain domain. nChain has the highest number of patent applications (78), followed by Coinplug (43), MasterCard (37), Alibaba Group (35), Nokia (22), Visa (21), CloudMinds (20), Walmart (18), Intel (15), and British Telecom (15). In particular, 43\% of nChain blockchain portfolio is classified in 'payment, transaction, user, item, management, online' domain, $29 \%$ regards 'communication, network, service, transmitting, computing, wireless', 22\% includes 'computing, processor, touch, display, content, memory', the remaining 5\% encompasses technological knowledge in 'machine learning, neural network, signal, satellite, access, base station', among others. The other companies seem to have a similar composition concentrated in these domains. However, each of them appears to develop specific technical knowledge that others do not have (referring to blockchain patents). For example, MasterCard has not developed inventions that include machine learning or neural network, but it has inventions that encompass 'game, play, wagering, casino, and lottery'. Nokia is the only one among the top ten firms with patented inventions in 'pill, medication, container, vial, dispensing, and bottle' domain. Additionally, Walmart has the most diversified composition, including 'payment, transaction, user, item, management, online', 'communication, network, service, transmitting, computing, wireless', 'computing, processor, touch, display, content, memory', 'radar, light detection and ranging, positioning', 'image, video, camera, display, decoding, pixel', 'robot', 'three dimensional, mold, composite, fiber', 'vehicle', and 'autonomous 
vehicle, drone, flight, aircraft'.

Besides, we are interested in providing insights into blockchain technology's essential traits, such as diversification (Note 1), novelty, and originality. The degree of diversification refers to the richness regarding various technology elements applied in the specific field. We used the number of different Derwent class codes included in the blockchain patents issued within a particular year. Figure 3 shows an impressive increase from 4 different class codes in 2008 to 54 in 2017. The blockchain domain broadens its technological components, increasing the potential combinations and fostering diffusion in other fields.

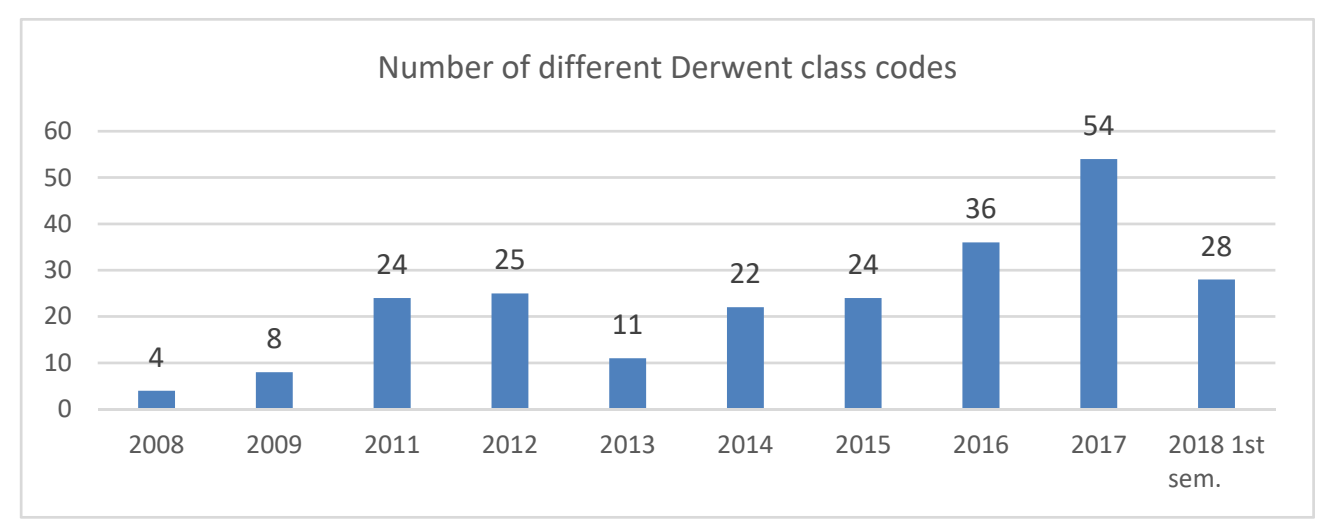

Figure 3. Number of different Derwent classification codes for each application year

Additionally, the degree of novelty captures the breadth of technology domains included in a patented invention, while patent originality captures the breadth of diverse technology fields included in the focal patent's prior art. Following Makri, Hitt, \& Lane (2010), our measure of novelty is formalized as follows: Novelty $y_{i}=1-\sum_{j=1}^{n_{i}} t s_{i j}^{2}$ where $s_{i j}$ indicates the proportion of technological classes that patent holds in class $j$ among $n$ total number of technological classes. Since we are interested to understand better the originality of inventions belonging to the blockchain domain, we used a Herfindahl-Hirschman indicator based on the technological classification of the backward citations of a specific patented invention (Hall et al., 2001). It is assessed as follows: Originality $y_{i}=1-$ $\sum_{j=1}^{n_{i}} t_{i j}^{2}$ where $t_{i j}$ denotes the proportion of the citations made by patent $t_{i}$ to preceding patents that belonged to various technological classes $s_{j}$ out of $n_{i}$ patent technological classes.

Both average patent novelty and average patent originality follow a similar path (Figure 4). They seem to increase in the first part of our timeframe and decrease after that. This result should be taken into account in the light that in the first 5-year time frame, there were only a few patent applications (26 patents) while we observe a rapid increase in the last years. Moreover, a plausible explanation regarding the observed average originality is that when a technology is in its very early stage of emergence, there might be no prior art of that specific field. Hence, inventors have to cite many patents widening in this way, the technology range of these citations. Indeed, these early patents can serve as the building platform for subsequent patents. Interestingly, the average originality is always higher than the average novelty, suggesting that blockchain technology is continually broadening the technological knowledge which it is built upon. 


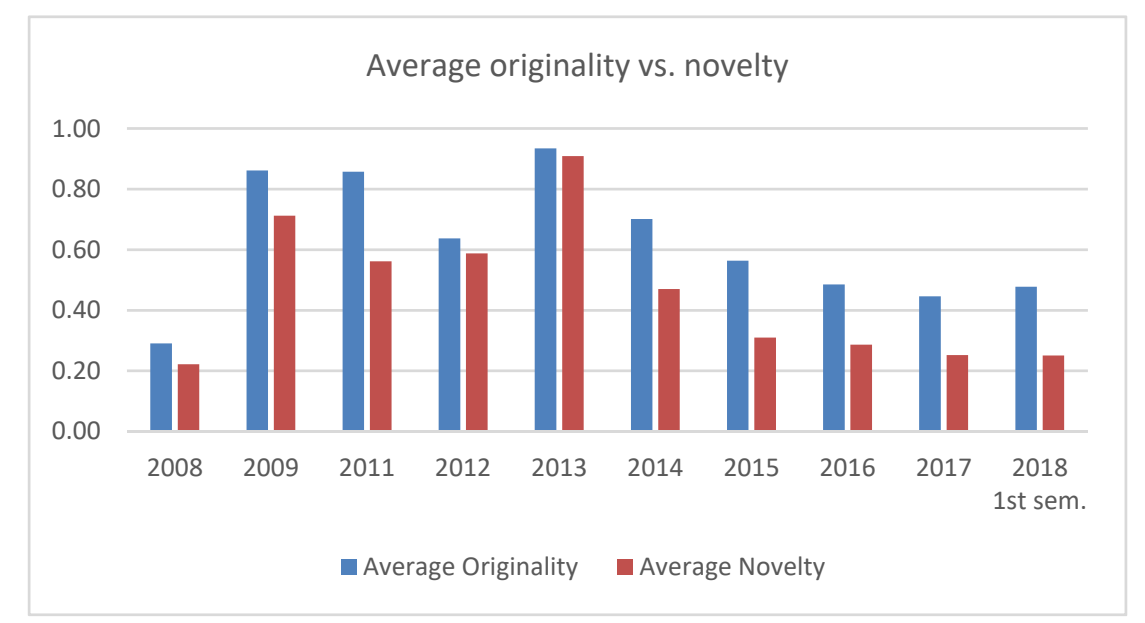

Figure 4. Average patent originality vs. average patent novelty for each application year

The decreasing trend (Figure 4) required a further investigation of the distribution of both novelty and originality measures. Figure 5 depicts the kernel density of the degree of novelty. The distribution is highly skewed following a double path. We observe the proliferation of specializing patents of the blockchain domain that belongs to a very narrow space and the generation of broad-spanning patents with a very high degree of novelty.

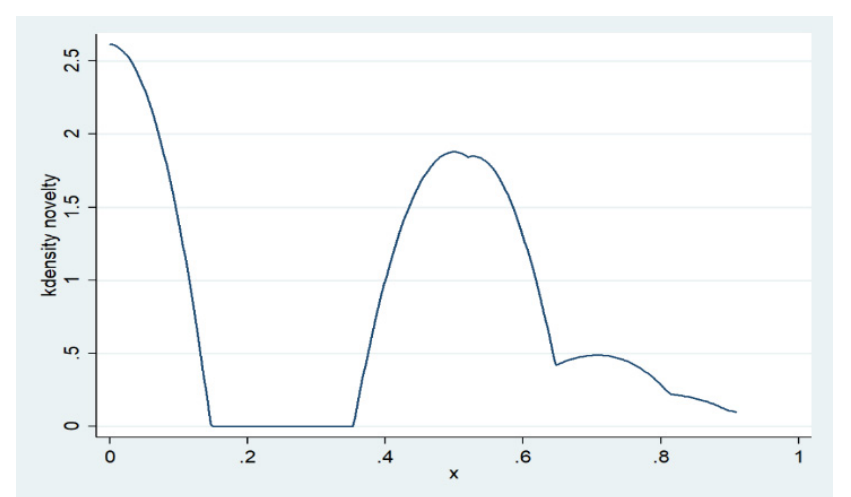

Figure 5. Kernel density of patent novelty (2008-2018 $1^{\text {st }}$ semester)

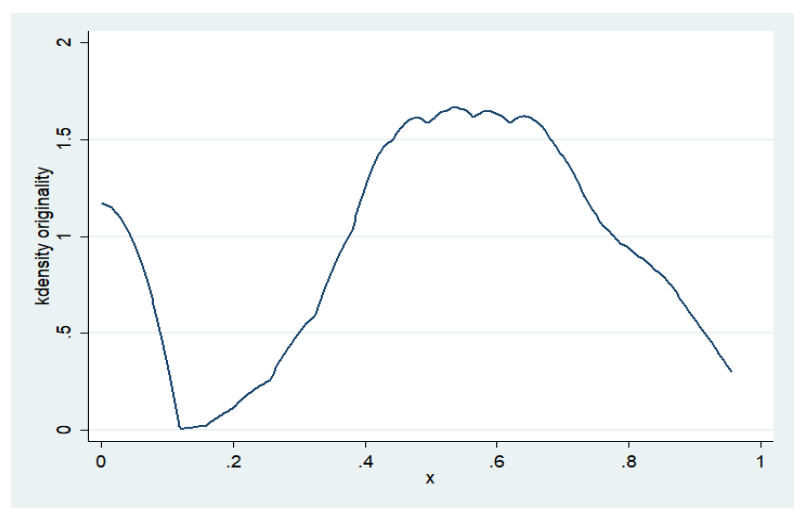

Figure 6. Kernel density of patent originality (2008-2018 $1^{\text {st }}$ semester)

As evidenced by the kernel density of the degree of originality in Figure 6, although most patents have high originality concerning the breadth of technological knowledge included in an invention, a group of patents is built upon a very focused technology domain — both novelty and originality show similar behavior. 


\subsection{Blockchain Technology Structure}

For the examination of the technology structure of the blockchain field, we used the technology classification codes. Figure 7 depicts the technology structure in the period that goes from 2008 to 2012. This window encompasses the earliest step of the emergence of the blockchain domain; the sample includes only 26 patents. As we can observe, the field presents a polycentric structure with many links within clusters and a few between them. No core technology is evident.

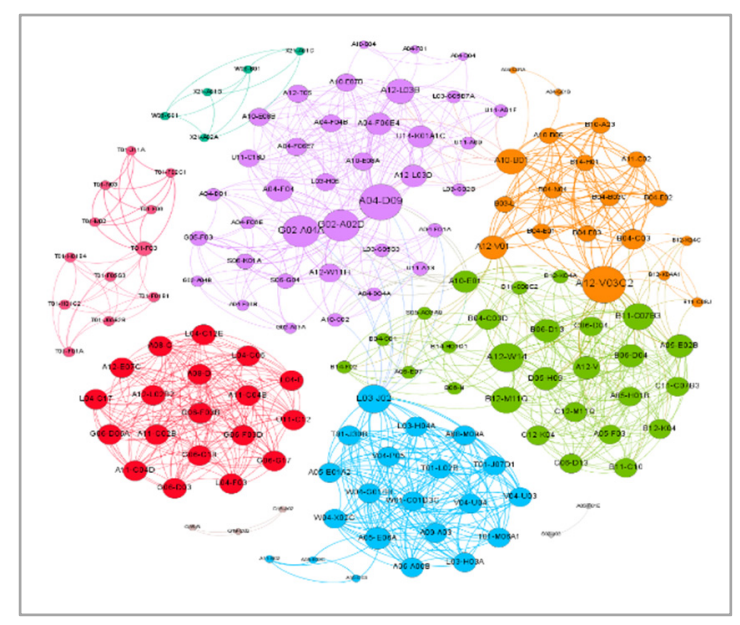

Figure 7. Blockchain technology structure (2008-2012)

Moreover, in this paper, we are particularly interested in unveiling the underlying technology structure of the blockchain domain. Figure 8 illustrates the different clusters and links between technological codes of the backward citations of blockchain patents. Although the number of technological codes included in the prior art is higher than the blockchain focal patents, the structure is similar: polycentric with few interconnections between clusters.

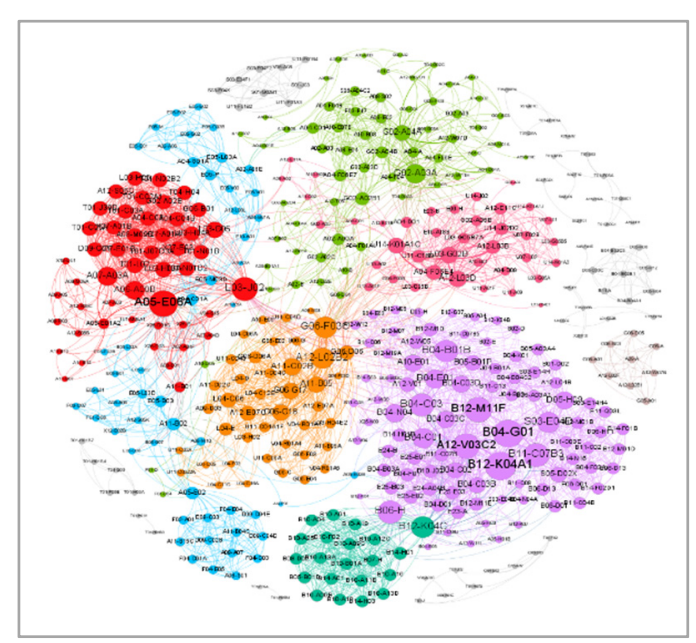

Figure 8. Technology structure of backward citations of blockchain patents (2008-2012)

As it emerges from Figure 9 in the second period from 2013 to the first semester of 2018, the technology structure changes radically. Nodes show a very high degree with a high density of interconnections with many other technology classes. The structure is similar to a hurricane, and the core drags a dense cloud of technology classes. Some of them are connected with other technology classes positioned at the frontier of the field.

The core structure evidenced by the most prominent nodes (see Figure 9) consists of five technology classes that 
include: (1) T01-J12C 'Preventing unauthorised access to files and processing systems such as anti-hacking and copy protection, electronic security systems for computers'; (2) T01-N02B1B 'Using password covers, password systems for gaining access to computer system'; (3) T01-D01 'Data encryption and decryption including private and public key encryption'; (4) W01-A05A 'Blockwise coding using registers and memories including DES (Data encryption standard) and AES (Advance encryption standard) systems, and key distribution, cryptographic communication, public key, private key'; and (5) T01-S03 'Claimed software products, claimed products based on software, and stored'. Not surprisingly, since the blockchain domain is within the information and communication technology sector, we find 'Digital computers' (T01) and 'Telephone and data transmission systems' (W01). All nodes show high interconnectedness; however, the most active links occur between 'Data encryption and decryption' and 'Blockwise coding', 'Using Password Covers' and 'Preventing unauthorized access to files and processing systems'.

Observing the nodes' size clarifies the difference between the core and the other technological classes. The latter gravitate around the core with a high interconnectedness between them. The blockchain domain presents a coreperiphery network, which according to Korzinov et al. (2018), fosters the speed of technological knowledge diffusion and generality. The more frequent classifcation codes that appear in the sampling patents belong to the 'Digital computer' subsection (T01) and include 'Data and directory structures including hashing, tree structures' (T01-J05B2B), 'File management and access' (T01-N02B1A), 'Comparing digital values, random number generators' (T01-E04), 'FinTech, cryptocurrency, electronic payment systems' (T01-N01A1), 'From remote site or server' (T01-N01D3), 'Data transfer' (T01-N01D), 'Database applications' (T01-J05B4P), 'File transfer' (T01-N01D2), 'Servers' (T01-N02A3C), 'Peer-to-peer networks' (T01-N02A2E), 'Internet business models' (T01-N01A2), 'Financial/Monetary' (T01-J05A1), 'Internet of Things' (T01-N01F), 'Metadata' (T01-J05B2C), 'Distributed database' (T01-J05B4A), 'Vehicle microprocessor system' (T01-J07D1), 'On-line medicine' (T01N01E1), 'Computer processing for sports and training equipment' (T01-J30D), 'Image analysis' (T01-J10B2), among others.

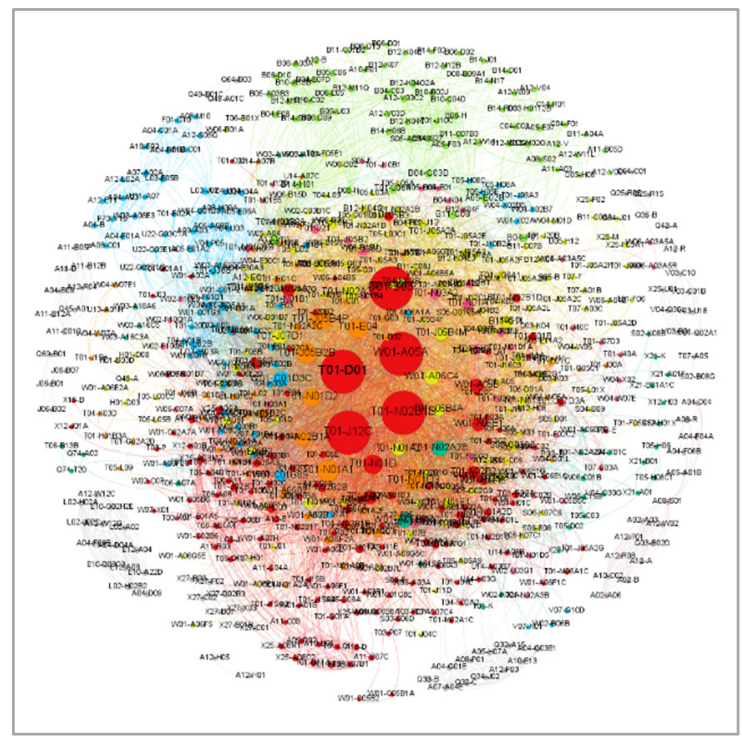

Figure 9. Blockchain technology structure (2013-2018 $1^{\text {st }}$ semester)

Among the classification classes included in the subsection 'Telephone and data transmission systems' (W01), we observe 'Identity verification/access control' (W01-A05B), 'Access and routing' (W01-A06E1), 'Radio link' (W01-A06C4), 'Mobile phone' (W01-C01D3C), and 'Smartphone' (W01-C01G8S). There are present other four technology classes belonging to other technology classes: 'General computing methods \& apparatus' (B11-C11), '3D printing/additive manufacturing methods' (X25-A08A), 'Data transfer/storage methods and apparatus' (S05G02G3), and 'Medicines and pharmaceuticals' (A12-V01).

Going more in detail to the landscape depicted in Figure 9, we can add some considerations. A first emerging result consists of the spanning of technology boundaries, moving from two technology classification sections that encompass core technologies (i.e., T - 'Computing and control', W - 'Communications') to almost all sections 
(except section $\mathbf{K}$ - 'Nucleonics, explosives, and protection'), namely, $\mathbf{X}$ - 'Electric power engineering', $\mathbf{S}$ 'Instrumentation, measuring, and testing', B - 'Pharmaceuticals', A - 'Polymers and plastics', U 'Semiconductors and electronic circuitry', V - 'Electronic components', P - 'General', Q - 'Mechanical', G'Printing, coating, and photographic', C - 'Agricultural chemicals', D - 'Food, detergents, water treatment, and biotechnology', E - 'General chemicals', F - 'Textiles and paper-making', H - 'Petroleum', J - 'Chemical engineering', and $\mathbf{L}$ - 'Refractories, ceramics, cement, and electro(in)organics'.

Finally, another important indicator when investigating the technology network is the betweenness centrality that quantifies the number of times a specific node acts as a bridge along the shortest path between two other nodes. Network analysis shows that the nodes with the highest betweenness centrality are the five nodes that compose the core structure with four technology classes 'Financial/Business', 'From remote site or server', 'Database applications', and 'Peer-to-peer network'.

\section{Discussions and Conclusions}

In this paper, we disentangled the technology structure, evolution, and trends of the blockchain domain by adopting a patent co-classification analysis. The examination of 964 international patents issued from 2008-2018 (1 $1^{\text {st }}$ semester) showed a proliferation of the inventive activity outputs and a significant increase in the diversification across different technology fields. The results on novelty and originality are consistent with the 'space for improvement' and 'pervasiveness' characteristics of a GPT. Thus, observing these dynamics, we can hypothesize that from a technology perspective, blockchain has great potentiality to become a GPT. Our mapping and visualization analysis revealed that blockchain technology is characterized by a centric structure with strong links between technologies. This might signal that blockchain is building its platform. The game is still open.

This paper contributes to the existing literature in several ways. It contributes to the technology innovation literature by uncovering the emergence and evolutionary dynamics of the blockchain field. A study of Kaplan and Vakili (2015) using a sample of GPT patents (nanotechnology) highlighted the double-edged sword feature of recombination. The authors pointed out that highly impactful inventions could arise either from focused or broad knowledge. An explanation of their results might depend on the dual-path pattern of the GPT.

Furthermore, from a more practical perspective, our paper can help technology scholars in their blockchain studies by providing a taxonomy of the technology classification codes that include the core technology elements of this field and those highly related. An additional consideration is that blockchain's technology structure visualized in our maps is consistent and follows the intuition of engineering studies (Ferrag et al., 2018), confirming the strong linkage between science and the emergence and evolution of impactful technologies.

As with any emerging technology, the current scenario is full of uncertainty. Therefore, providing a clear picture of these dynamics can offer new and additional understandings of the phenomenon. Bringing to the knowledge what potential competitors/partners are working on can be useful for both firms already in the blockchain technology market and those who want to enter it. Our exploration of the blockchain landscape can be helpful to managers in their decision-making about how to design R\&D activities in this field, drive organizations with a new vision about the opportunities that emerge regarding blockchain, and choose the most suitable position in the technological space (for instance, trying to patent platform inventions).

We mapped and visualized a comprehensive overview of blockchain technology and discussed its dynamics in an international scenario. Our work can also help policymakers who can increase awareness of the potentiality of this technology and drive regulation consistently, especially in standard settings. In order to respond to the question of whether blockchain technology will become a reality, particular attention should be drawn to several factors, such as foster knowledge diffusion and concentrate R\&D efforts (Korzinov \& Savin, 2018).

Despite the contributions mentioned above, the present work has several drawbacks. A first limitation is related to patent analysis. Not all inventions are patentable because they do not fulfill the patentability criteria, or firms may choose to rely on secrecy (Ardito, D'Adda, \& Petruzzelli, 2018). Future studies may examine the underlying mechanism that allows technological elements to move in the technological space, what forces drive them under the technology specificities. Finally, in this paper, we did not have information on forward citation given the early stage of the emergence of blockchain technology; thus, other works can further investigate the generality features of blockchain by analyzing future patents' various domains. 


\section{References}

Ahuja, G., \& Lampert, C. (2001). Entrepreneurship in the large corporation: A longitudinal study of how established firms create breakthrough inventions. Strategic Management Journal, 22(6-7), 521-543. https://doi.org/10.1002/smj.176

Andoni, M., Robu, V., Flynn, D., Abram, S., Geach, D., Jenkins, D., ... \& Peacock, A. (2019). Blockchain technology in the energy sector: A systematic review of challenges and opportunities. Renewable and Sustainable Energy Reviews, 100, 143-174. https://doi.org/10.1016/j.rser.2018.10.014

Ardito, L., D'Adda, D., \& Petruzzelli, A. M. (2018). Mapping innovation dynamics in the Internet of Things domain: Evidence from patent analysis. Technological Forecasting and Social Change, 136, 317-330. https://doi.org/10.1016/j.techfore.2017.04.022

Ardito, L., Petruzzelli, A. M., \& Albino, V. (2016). Investigating the antecedents of general purpose technologies: A patent perspective in the green energy field. Journal of Engineering and Technology Management, 39, 81100. https://doi.org/10.1016/j.jengtecman.2016.02.002

Bresnahan, T. (2010). General purpose technologies. In Handbook of the Economics of Innovation (Vol. 2, pp. 761-791). North-Holland. https://doi.org/10.1016/S0169-7218(10)02002-2

Bresnahan, T. F., \& Trajtenberg, M. (1995). General purpose technologies 'Engines of growth'? Journal of econometrics, 65(1), 83-108. https://doi.org/10.1016/0304-4076(94)01598-T

Calcagno, M. (2008). An investigation into analyzing patents by chemical structure using Thomson's Derwent World Patent Index codes. World Patent Information, 30(3), 188-198. https://doi.org/10.1016/j.wpi.2007.10.007

Castriotta, M., \& Di Guardo, M. C. (2016). Disentangling the automotive technology structure: a patent co-citation analysis. Scientometrics, 107(2), 819-837. https://doi.org/10.1007/s11192-016-1862-0

Castriotta, M., Loi, M., Marku, E., \& Naitana, L. (2019). What's in a name? Exploring the conceptual structure of emerging organizations. Scientometrics, 118(2), 407-437.https://doi.org/10.1007/s11192-018-2977-2

Chuen, D. L. K., \& Deng, R. H. (2017). Handbook of Blockchain, Digital Finance, and Inclusion: Cryptocurrency, FinTech, InsurTech, Regulation, ChinaTech, Mobile Security, and Distributed Ledger. Academic Press.

Conti, R., Gambardella, A., \& Novelli, E. (2019). Specializing in general purpose technologies as a firm long-term strategy. Industrial and Corporate Change, 28(2), 351-364. https://doi.org/10.1093/icc/dty069

Criscuolo, P., \& Verspagen, B. (2008). Does it matter where patent citations come from? Inventor vs. examiner citations in European patents. Research Policy, 37(10), 1892-1908. https://doi.org/10.1016/j.respol.2008.07.011

Curran, C. S., \& Leker, J. (2011). Patent indicators for monitoring convergence-examples from NFF and ICT. Technological Forecasting and Social Change, 78(2), 256-273. https://doi.org/10.1016/j.techfore.2010.06.021

De Soto, H. (2017). A tale of two civilizations in the era of Facebook and blockchain. Small Business Economics, 49(4), 729-739. https://doi.org/10.1007/s11187-017-9949-4

Dierksmeier, C., \& Seele, P. (2018). Cryptocurrencies and business ethics. Journal of Business Ethics, 152(1), 114. https://doi.org/10.1007/s10551-016-3298-0

Di Guardo, M. C., \& Harrigan, K. R. (2012). Mapping research on strategic alliances and innovation: a co-citation analysis. The Journal of Technology Transfer, 37(6), 789-811. https://doi.org/10.1007/s10961-011-9239-2

Di Guardo, M. C., Harrigan, K. R., \& Marku, E. (2019). M\&A and diversification strategies: what effect on quality of inventive activity?. Journal of Management and Governance, 23(3), 669-692. https://doi.org/10.1007/s10997-018-9437-5

Dorri, A., Steger, M., Kanhere, S. S., \& Jurdak, R. (2017). Blockchain: A distributed solution to automotive security and privacy. IEEE Communications Magazine, 55(12), 119-125. https://doi.org/10.1109/MCOM.2017.1700879

Efanov, D., \& Roschin, P. (2018). The All-Pervasiveness of the Blockchain Technology. Procedia Computer Science, 123, 116-121. https://doi.org/10.1016/j.procs.2018.01.019

Engelhardt, M. A. (2017). Hitching healthcare to the chain: An introduction to blockchain technology in the healthcare sector. Technology Innovation Management Review, 7(10), 22-34. 
Esposito, C., De Santis, A., Tortora, G., Chang, H., \& Choo, K. K. R. (2018). Blockchain: A Panacea for Healthcare Cloud-Based Data Security and Privacy? IEEE Cloud Computing, 5(1), 31-37.

Felin, T., \& Lakhani, K. (2018). What problems will you solve with blockchain? Mit Sloan Management Review, $60(1), 32-38$.

Ferrag, M. A., Derdour, M., Mukherjee, M., Derhab, A., Maglaras, L., \& Janicke, H. (2018). Blockchain technologies for the internet of things: Research issues and challenges. IEEE Internet of Things Journal, 6(2), 2188-2204. https://doi.org/10.1109/JIOT.2018.2882794

Fisch, C. (2019). Initial coin offerings (ICOs) to finance new ventures. Journal of Business Venturing, 34(1), 1-22. https://doi.org/10.1016/j.jbusvent.2018.09.007

Conti, R., Gambardella, A., \& Novelli, E. (2019). Specializing in Generality: Firm Strategies When Intermediate Markets Work. Organization Science, 30(1), 126-150. https://doi.org/10.1287/orsc.2018.1243

Gambardella, A., Giarratana, M., (2015). General-Purpose Technology, The Palgrave Encyclopedia of Strategic Management. Palgrave Macmillan, Basingstoke. https://doi.org/10.1057/978-1-349-94848-2_345-1

Gambardella, A., \& McGahan, A. M. (2010). Business-model innovation: General purpose technologies and their implications for industry structure. Long Range Planning, 43(2-3), 262-271. https://doi.org/10.1016/j.lrp.2009.07.009

Gambardella, A., \& Giarratana, M. S. (2013). General technological capabilities, product market fragmentation, and markets for technology. Research Policy, 42(2), 315-325. https://doi.org/10.1016/j.respol.2012.08.002

Gu, J., Sun, B., Du, X., Wang, J., Zhuang, Y., \& Wang, Z. (2018). Consortium Blockchain-Based Malware Detection in Mobile Devices. IEEE Access, 6, 12118-12128. https://doi.org/10.1109/ACCESS.2018.2805783

Hall, B. H., Jaffe, A. B., \& Trajtenberg, M. (2001). The NBER patent citation data file: Lessons, insights and methodological tools (No. w8498). National Bureau of Economic Research. https://doi.org/10.3386/w8498

Hall, B. H., \& Trajtenberg, M. (2006). Uncovering general purpose technologies with patent data. In C. Antonelli, D. Foray, B. H. Hall, \& E. W. Steinmuller (Eds.), New frontiers in the economics of innovation and new technology (pp. 389-426). Cheltenham: Edward Elgar.

Harrigan, K. R., Di Guardo, M. C., \& Marku, E. (2018). Patent value and the Tobin's q ratio in media services. The Journal of Technology Transfer, 43(1), 1-19. https://doi.org/10.1007/s10961-017-9564-1

Harrigan, K. R., Di Guardo, M. C., Marku, E., \& Velez, B. N. (2017). Using a distance measure to operationalise patent originality. Technology Analysis \& Strategic Management, 29(9), 988-1001.

Hawlitschek, F., Notheisen, B., \& Teubner, T. (2018). The limits of trust-free systems: A literature review on blockchain technology and trust in the sharing economy. Electronic Commerce Research and Applications, 29, 50-63. https://doi.org/10.1016/j.elerap.2018.03.005

Helpman, E., \& Trajtenberg, M. (1994). A time to sow and a time to reap: Growth based on general purpose technologies (No. w4854). National Bureau of Economic Research. https://doi.org/10.3386/w4854

Holotiuk, F., Pisani, F., \& Moormann, J. (2019). Radicalness of blockchain: an assessment based on its impact on the payments industry. Technology Analysis \& Strategic Management, 31(8), 915-928. https://doi.org/10.1080/09537325.2019.1574341

Huang, X., Xu, C., Wang, P., \& Liu, H. (2018). Lnsc: A security model for electric vehicle and charging pile management based on blockchain ecosystem. IEEE Access, (99), 1. https://doi.org/10.1109/ACCESS.2018.2812176

Iansiti, M., \& Lakhani, K. R. (2017). The truth about blockchain. Harvard Business Review, 95(1), 118-127.

Jaffe, A. B. (1986). Technological opportunity and spillovers of R\&D: evidence from firms' patents, profits and market value. American Economic Review, 76(5), 984-1001. https://www.nber.org/papers/w1815

Janse van Rensburg, A., Petersen, I., Wouters, E., Engelbrecht, M., Kigozi, G., Fourie, P., ... \& Bracke, P. (2018). State and non-state mental health service collaboration in a South African district: a mixed methods study. Health Policy and Planning, 33(4), 516-527. https://doi.org/10.1093/heapol/czy017

Kaplan, S., \& Vakili, K. (2015). The double-edged sword of recombination in breakthrough innovation. Strategic Management Journal, 36(10), 1435-1457. https://doi.org/10.1002/smj.2294

Karvonen, M., \& Kässi, T. (2013). Patent citations as a tool for analysing the early stages of convergence. 
Technological Forecasting and Social Change, 80(6), https://doi.org/10.1016/j.techfore.2012.05.006

Khalilov, M. C. K., \& Levi, A. (2018). A Survey on Anonymity and Privacy in Bitcoin-like Digital Cash Systems. IEEE Communications Surveys \& Tutorials, 20 2543-2585. https://doi.org/10.1109/COMST.2018.2818623

Kim, G., \& Bae, J. (2017). A novel approach to forecast promising technology through patent analysis. Technological Forecasting and Social Change, 117, 228-237. https://doi.org/10.1016/j.techfore.2016.11.023

Korzinov, V., \& Savin, I. (2018). General Purpose Technologies as an emergent property. Technological Forecasting and Social Change, 129, 88-104. https://doi.org/10.1016/j.techfore.2017.12.011

Lacity, M. (2018). Addressing Key Challenges to Making Enterprise Blockchain Applications a Reality. MIS Quarterly Executive, 17(3), 201-222.

Larios-Hernández, G. J. (2017). Blockchain entrepreneurship opportunity in the practices of the unbanked. Business Horizons, 60(6), 865-874. https://doi.org/10.1016/j.bushor.2017.07.012

Lee, C., Kang, B., \& Shin, J. (2015). Novelty-focused patent mapping for technology opportunity analysis. Technological Forecasting and Social Change, 90, 355-365. https://doi.org/10.1016/j.techfore.2014.05.010

Lee, C., Park, G., \& Kang, J. (2018). The impact of convergence between science and technology on innovation. The Journal of Technology Transfer, 43(2), 522-544. https://doi.org/10.1007/s10961-016-9480-9

Leydesdorff, L. (2008). Patent classifications as indicators of intellectual organization. Journal of the Association for Information Science and Technology, 59(10), 1582-1597. https://doi.org/10.1002/asi.20814

Li, L., Liu, J., Cheng, L., Qiu, S., Wang, W., Zhang, X., \& Zhang, Z. (2018). CreditCoin: A Privacy-Preserving Blockchain-Based Incentive Announcement Network for Communications of Smart Vehicles. IEEE Transactions on Intelligent Transportation Systems, 19(7), 2204-2220. https://doi.org/10.1109/TITS.2017.2777990

Lipsey, R. G., Carlaw, K. I., \& Bekar, C. T. (2005). Economic transformations: general purpose technologies and long-term economic growth. OUP Oxford.

Loi, M., Castriotta, M., \& Di Guardo, M. C. (2016). The theoretical foundations of entrepreneurship education: How co-citations are shaping the field. International Small Business Journal, 34(7), 948-971. https://doi.org/10.1177/0266242615602322

Luan, C., Liu, Z., \& Wang, X. (2013). Divergence and convergence: technology-relatedness evolution in solar energy industry. Scientometrics, 97(2), 461-475. https://doi.org/10.1007/s11192-013-1057-x

Makri, M., Hitt, M. A., \& Lane, P. J. (2010). Complementary technologies, knowledge relatedness, and invention outcomes in high technology mergers and acquisitions. Strategic Management Journal, 31(6), 602-628. https://doi.org/10.1002/smj.829

Marku, E., Castriotta, M., Di Guardo, M. C., \& Loi, M. (2019). Mapping innovation in the digital transformation era: The role of technology convergence. In Business transformations in the era of digitalization (pp. 160178). IGI Global. https://doi.org/10.4018/978-1-5225-7262-6.ch010

Marsal-Llacuna, M. L. (2018). Future living framework: Is blockchain the next enabling network? Technological Forecasting and Social Change, 128, 226-234.

McCain, K. W. (1990). Mapping authors in intellectual space: A technical overview. Journal of the American Society for Information Science, 41(6), 433-443. https://doi.org/10.1002/(SICI)10974571(199009)41:6\%3C433::AID-ASI11\%3E3.0.CO;2-Q

Miau, S., \& Yang, J. M. (2018). Bibliometrics-based evaluation of the Blockchain research trend: 2008-March 2017. Technology Analysis \& Strategic Management, 30(9), 1029-1045. https://doi.org/10.1080/09537325.2018.1434138

Moser, P., \& Nicholas, T. (2004). Was electricity a general purpose technology? Evidence from historical patent citations. American Economic Review, 94(2), 388-394. https://doi.org/10.1257/0002828041301407

Oh, C., Cho, Y., \& Kim, W. (2015). The effect of a firm's strategic innovation decisions on its market performance. Technology Analysis \& Strategic Management, 27(1), 39-53.

Önder, I., \& Treiblmaier, H. (2018). Blockchain and tourism: Three research propositions. Annals of Tourism Research, 72(C), 180-182. https://doi.org/10.1016/j.annals.2018.03.005 
Pazaitis, A., De Filippi, P., \& Kostakis, V. (2017). Blockchain and value systems in the sharing economy: The illustrative case of Backfeed. Technological Forecasting and Social Change, 125, 105-115. https://doi.org/10.1016/j.techfore.2017.05.025

Seidel, M. D. L. (2018). Questioning Centralized Organizations in a Time of Distributed Trust. Journal of Management Inquiry, 27(1), 40-44. https://doi.org/10.1177/1056492617734942

Shea, C. M., Grinde, R., \& Elmslie, B. (2011). Nanotechnology as general-purpose technology: empirical evidence and implications. Technology Analysis \& Strategic Management, 23(2), 175-192. https://doi.org/10.1080/09537325.2011.543336

Swan, M. (2015). Blockchain: Blueprint for a new economy. O’Reilly Media, Inc.

Syverson, C. (2013). Will History Repeat Itself? Comments on "Is the Information Technology Revolution Over?" International Productivity Monitor, (25), 37-40. $\quad$ Retrieved from http://home.uchicago.edu/syverson/ITrevolution.pdf

Tapscott, D., \& Tapscott, A. (2017). How blockchain will change organizations. MIT Sloan Management Review, $58(2), 10-13$.

Trajtenberg, M. (1990). A penny for your quotes: patent citations and the value of innovations. The Rand Journal of Economics, 172-187. https://doi.org/10.2307/2555502

Trappey, C. V., Wu, H. Y., Taghaboni-Dutta, F., \& Trappey, A. J. (2011). Using patent data for technology forecasting: China RFID patent analysis. Advanced Engineering Informatics, 25(1), 53-64. https://doi.org/10.1016/j.aei.2010.05.007

Veuger, J. (2018). Trust in a viable real estate economy with disruption and blockchain. Facilities, 36(1/2), 103120. https://doi.org/10.1108/F-11-2017-0106

$\mathrm{Xu}, \mathrm{C}$., Wang, K., \& Guo, M. (2017). Intelligent resource management in blockchain-based cloud datacenters. IEEE Cloud Computing, 4(6), 50-59. https://doi.org/10.1109/MCC.2018.1081060

Yoo, S. (2017). Blockchain based financial case analysis and its implications. Asia Pacific Journal of Innovation and Entrepreneurship, 11(3), 312-321. https://doi.org/10.1108/APJIE-12-2017-036

Youtie, J., Iacopetta, M., \& Graham, S. (2008). Assessing the nature of nanotechnology: can we uncover an emerging general purpose technology? The Journal of Technology Transfer, 33(3), 315-329. https://doi.org/10.1007/s10961-007-9030-6

Zalan, T. (2018). Born global on blockchain. Review of International Business and Strategy, 28(1), 19-34. https://doi.org/10.1108/RIBS-08-2017-0069

Zupic, I., \& Čater, T. (2015). Bibliometric methods in management and organization. Organizational Research Methods, 18(3), 429-472. https://doi.org/10.1177/1094428114562629

\section{Note}

Note 1. For the assessment of the indicators of diversification, novelty, and originality, we used Derwent class codes (4 digits) to reduce redundancy within the same class.

\section{Copyrights}

Copyright for this article is retained by the author(s), with first publication rights granted to the journal.

This is an open-access article distributed under the terms and conditions of the Creative Commons Attribution license (http://creativecommons.org/licenses/by/4.0/). 